\title{
Abastecimento rural de água: uso e demanda em comunidades do Semiárido e a disponibilidade hídrica das aluviões
}

\author{
Rural water supply: use and demand in semiarid \\ communities and water availability of alluviums
}

Tiago Oliveira Caetano ${ }^{1}$, Anderson Luiz Ribeiro de Paiva ${ }^{1}$, Simone Rosa da Silva ${ }^{2}$, Artur Paiva Coutinho ${ }^{1}$, José Almir Cirilo ${ }^{1}$, Jaime Joaquim da Silva Pereira Cabral ${ }^{1,2}$

${ }^{1}$ Universidade Federal de Pernambuco - UFPE, Recife, PE, Brasil. E-mails: tiagooliveiracaetano@hotmail.com, andersonlrpaiva@gmail.com, arthur.coutinho@hotmail.com, almir.cirilo@gmail.com,

2Universidade de Pernambuco - UPE, Recife, PE, Brasil. E-mail: jcabral.ufpe@gmail.com, simonerosa@poli.br

Como citar: Caetano, T. O., Paiva, A. L. R., Silva, S. R., Coutinho, A. P., Cirilo J. A., \& Cabral, J. J. S. P. (2020). Abastecimento rural de água: uso e demanda em comunidades do Semiárido e a disponibilidade hídrica das aluviões. Revista de Gestão de Água da América Latina, 17, e8. https://doi.org/10.21168/rega.v17e8

RESUMO: Ofertar água em quantidade e qualidade necessárias no semiárido brasileiro é um desafio longe de ser superado, ainda mais quando se trata de comunidades rurais difusas. Conhecer usos, demandas e fontes de água é vital para melhor gerenciamento em cenário de escassez hídrica. As aluviões são uma alternativa considerável na perspectiva de melhor convivência com esta realidade. Para o trecho no Alto Rio Capibaribe, identificou-se as características de uso, as demandas e os tipos de mananciais hídricos mais relevantes em comunidades rurais no semiárido. Também se avaliou a disponibilidade hídrica da aluvião na área. Obteve-se a granulometria, os parâmetros de condutividade hidráulica e porosidade e a estimativa dos recursos exploráveis. A população usa água de diferentes fontes de forma combinada. A água das cisternas é usada quase que exclusivamente nas atividades domésticas mais nobres, enquanto a armazenada na aluvião é usada prioritariamente nas menos nobres e na agricultura familiar e criação animal. De maneira geral, a limitação de acesso a água determina quais atividades produtivas podem ser realizadas. Os sedimentos que compõem a aluvião foram classificados como areias de médias a grossas. 0 potencial estimado de volume de água explorável das aluviões as credenciaram como o principal manancial de abastecimento dessas comunidades.

Palavras-chave: Demanda Hídrica; Abastecimento de Comunidades Rurais; Aquífero Aluvial.

ABSTRACT: Offering water in quantity and quality needed in the Brazilian semiarid is a challenge far from being overcome, especially when it comes to diffuse rural communities. Knowing uses, demands and sources of water is vital for better management in a scenario of water scarcity. The alluviums are a considerable alternative in the perspective of better coexistence with this reality. For the stretch on the Upper Capibaribe River, the most relevant usage characteristics, demands and types of water sources in rural communities in the semiarid were identified. The water availability of the alluvium in the area was also evaluated. The granulometry, the parameters of hydraulic conductivity and porosity and the estimation of the exploitable resources were obtained. The population uses water from different sources in a combined way. Water from cisterns is used almost exclusively for the most noble domestic activities, while the water stored in the alluvium is used primarily for the less noble and for family farming and animal husbandry. In general, the limitation of access to water determines which productive activities can be carried out. The sediments that make up the alluvium were classified as medium to coarse sands. The estimated potential for exploitable water volume of the alluviums has accredited them as the main source of supply for these communities.

Keywords: Water Demand; Water Supply for Rural Communities; Alluvial Aquifer.

Recebido: Fevereiro 13, 2020. Revisado: Maio 04, 2020. Aceito: Junho 06, 2020. 


\section{INTRODUÇÃO}

O Brasil tem $1.128 .697 \mathrm{~km}^{2}$ do seu território configurado como região semiárida. Com uma população próxima de 30 milhões de habitantes, é a região árida ou semiárida mais habitada do planeta (Pernambuco, 2020). Pelos critérios de delimitação das Resoluções do Conselho Deliberativo da Sudene, são áreas com precipitação média anual menor que $800 \mathrm{~mm}$; índice de aridez de Thornthwaite igual ou inferior a 0,50; e percentual diário de déficit hídrico igual ou superior a $60 \%$, considerando todos os dias do ano (Pernambuco, 2017a, 2017b). A região possui altíssimos índices de evapotranspiração potencial (alcançando valores anuais entre 2.000 e $3.000 \mathrm{~mm}$ ), solos majoritariamente rasos e com embasamento rochoso e a quase totalidade dos seus rios são intermitentes (Moura et al., 2007; Cirilo et al., 2010). Resultando em uma disponibilidade hídrica per capita anual que chega a valores abaixo de $1.000 \mathrm{~m}^{3}$, bem menos que os $1.500 \mathrm{~m}^{3} / \mathrm{hab} /$ ano considerados pela Organização das Nações Unidas como a quantidade potencial de água mínima para o bem-estar e o desenvolvimento (Cirilo, 2008).

Os esforços para garantir o abastecimento hídrico de pessoas e animais e viabilizar a irrigação ainda não são, de forma global, suficientes. Parte considerável da população do Nordeste ainda continua vulnerável quando da ocorrência de secas (Gutiérrez et al., 2014; Marengo et al., 2016). Garantir a oferta de água em quantidade e qualidade necessárias nas zonas urbanas das cidades do semiárido ainda é um desafio presente e esse quadro é agravado se tratando da população rural difusa.

Além da questão da infraestrutura, é necessário conhecer mais as características do uso de água por essas populações, sendo possível ter melhor gestão e governança. 0 que pode ter mais impacto na vida das pessoas do que a magnitude do evento de seca ou mesmo o processo de mudanças climáticas (Silva et al., 2015).

Cerca de 38\% da população dos municípios da região vivem na zona rural (Medeiros et al., 2012). 0 abastecimento dessas pessoas, em geral, não se dará, de maneira economicamente viável, por meio de medidas convencionais, como grandes adutoras. É necessário encontrar alternativas para o melhor aproveitamento do potencial hídrico local, com medidas como a construção de cisternas para armazenamento de água das chuvas e o uso das águas acumuladas nas aluviões.

A aluvião é formada por sedimentos arrastados pelas correntezas e depositados nas calhas dos cursos d'água ao longo dos anos. São mananciais com reservas de água expressivas para o contexto do semiárido e, sobretudo, com uma proteção maior contra a evaporação, já que os próprios sedimentos criam uma camada protetora (Cirilo et al., 2010; Cabral et al., 2016).

Ao longo da extensa rede de rios e riachos intermitentes por todo semiárido, as populações fazem, há séculos, uso, em maior ou menor grau, das águas armazenadas nas aluviões (Cirilo et al., 2010; Paiva et al., 2014). Ainda assim, carece-se de maior conhecimento sobre a própria aluvião e sobre as características de uso e demanda de água dessas populações. Quais são as propriedades do manancial? Quanto se consome dessa água e quais usos são feitos? Quais outras fontes que são usadas por essas comunidades e para quais fins? Qual o volume de água disponível e a demanda hídrica?

0 presente trabalho buscou determinar as características de uso, demanda e fontes de água da população em comunidades rurais do semiárido e avaliar a disponibilidade hídrica das aluviões na mesma área, em trecho intermitente no Alto Rio Capibaribe-PE. Buscou-se contribuir para a caracterização da camada aluvial, para a estimativa do potencial explorável, para a identificação dos mananciais hídricos mais relevantes para essas populações, suas características de uso e finalidade de água e a obtenção de um balanço expedito de reversa versus demanda.

\section{METODOLOGIA}

A pesquisa foi desenvolvida desde as atividades do projeto Águas de Areais, realizado na região do Alto Capibaribe, com financiamento do programa Petrobrás Ambiental finalizado em 2015. Houve continuidade dos estudos hidrológicos na área, focando os aspectos hidrogeológicos e climáticos. As atividades desenvolvidas (Figura 1) podem ser agrupadas em 3 etapas: obtenção das características de uso e demanda de água da população no trecho estudado; estimativa do potencial hídrico das aluviões na área de estudo; confronto da demanda versus a reserva estimada. 


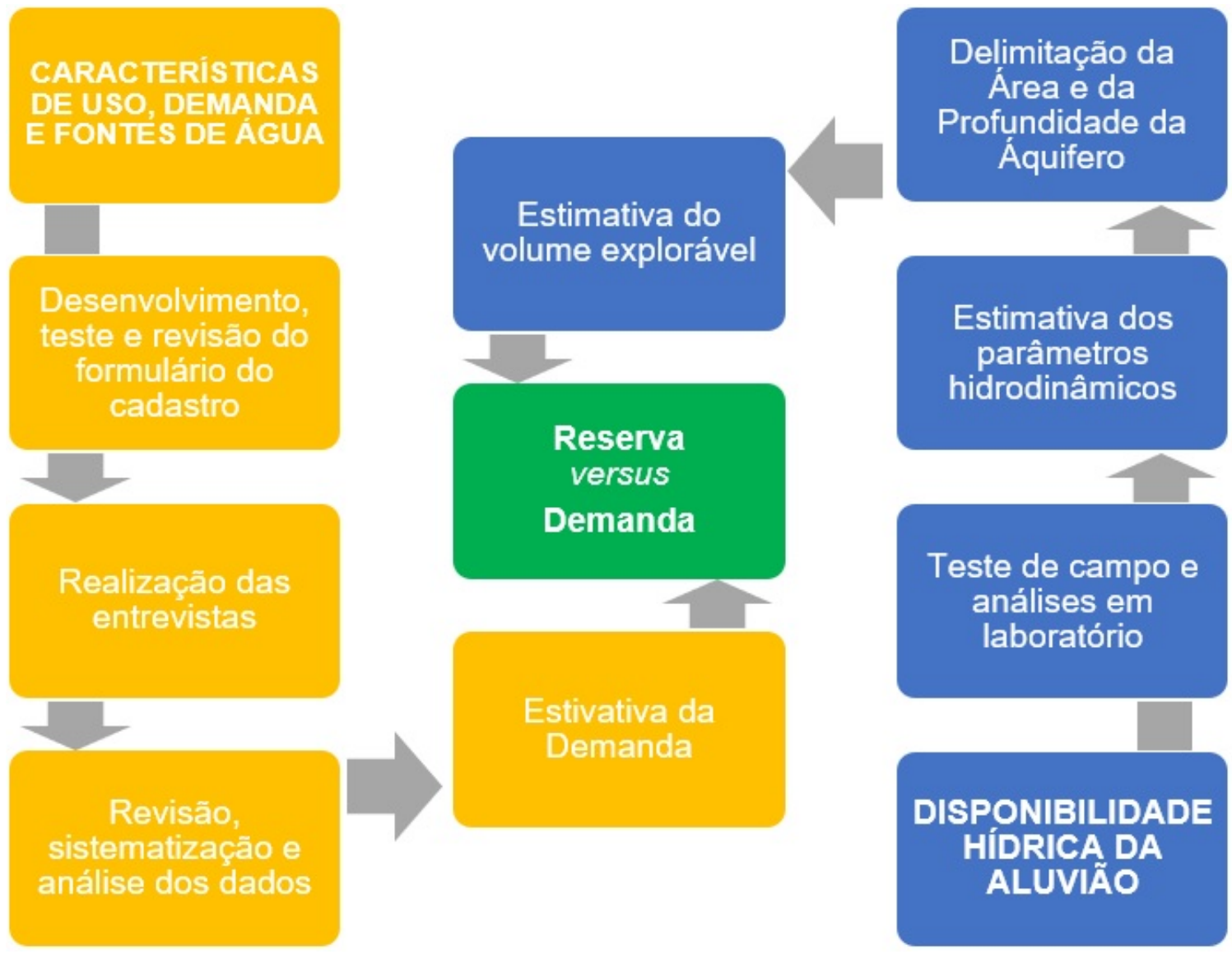

Figura 1 - Fluxograma da metodologia adotada para a pesquisa.

No período em que a pesquisa foi desenvolvida, 2014 a 2017, a região se encontrava assolada por uma seca que se prolongava desde 2012 (Cunha et al., 2019). Buscou-se também incorporar na análise os dados mais próximos da normalidade. 0 posto pluviométrico mais próximo da área dessa pesquisa (Posto 86 - Santa Cruz do Capibaribe) registrou pluviometria acumulada anual de 280,2 mm, quando a média anual histórica é de aproximadamente $600 \mathrm{~mm}$ (Agência Pernambucana de Águas e Clima, 2018). Assim sendo, deixa-se registrado que os resultados aqui apresentados são de uma pesquisa realizada nesta condição de escassez severa.

\section{1 Área de estudo}

A pesquisa foi realizada em um trecho do rio Capibaribe na mesorregião do Agreste Pernambucano (Figura 2). 0 trecho é parte da macrozona do Alto Capibaribe, onde o rio é intermitente e caracterizado por embasamento cristalino, relevos superiores a 400 metros, precipitação média anual de aproximadamente 600 milímetros e evapotranspiração potencial que chega a valores de 2000 mm/ano. A região apresenta déficit hídrico (Pernambuco, 2010; Braga et al., 2015).

0 trecho do rio Capibaribe que corresponde à área de estudo tem extensão de aproximadamente 9,00 km. Tem como limites o sítio Morcego - primeiro após o distrito de Poço Fundo, Santa Cruz do Capibaribe - e o encontro do riacho do Arapuá com o rio Capibaribe - região próxima à zona urbana de Santa Cruz do Capibaribe. 


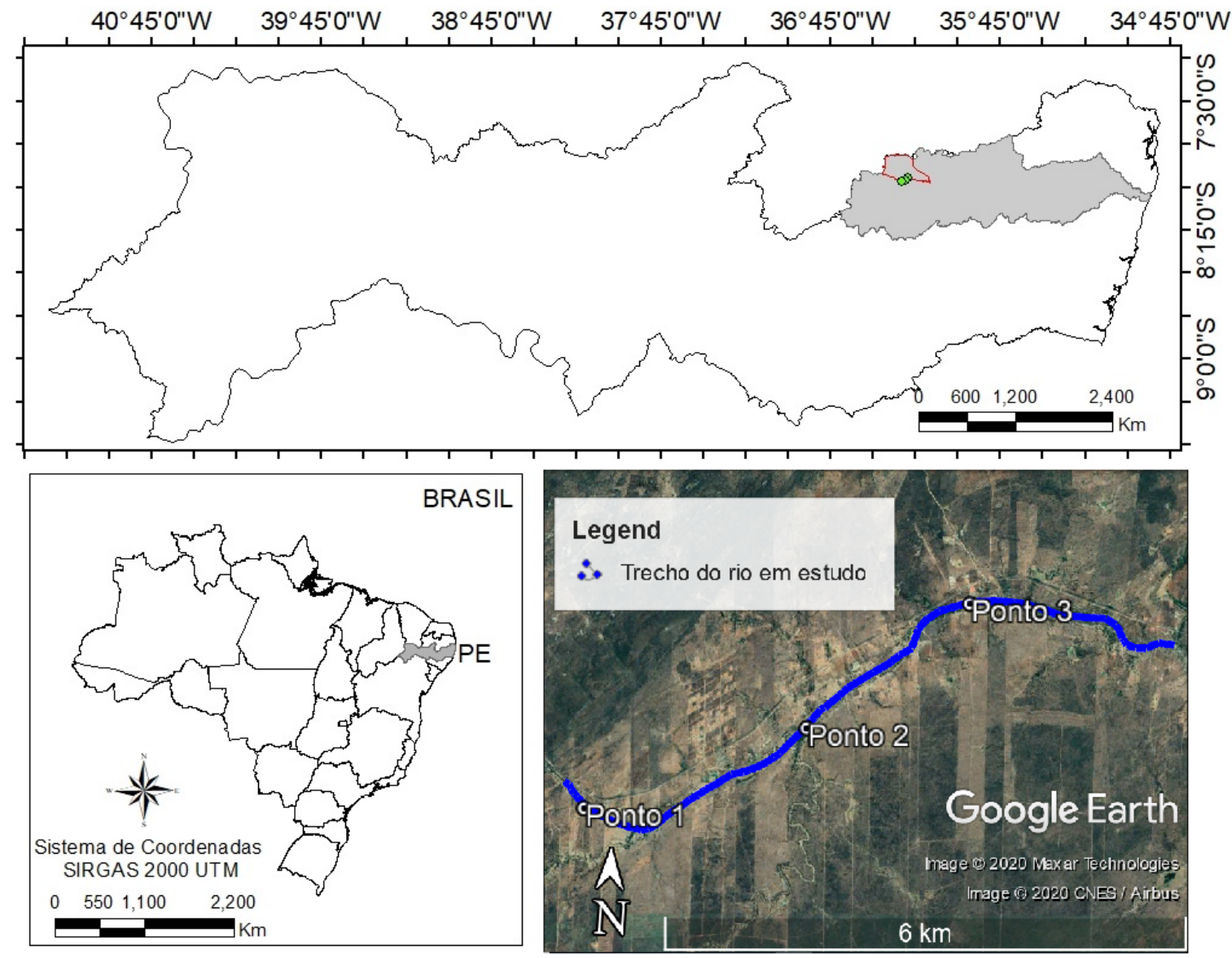

Figura 2 - Área de estudo na sub-bacia do Alto Capibaribe e posição dos pontos de coleta de amostras.

\subsection{Obtenção dos dados de usos, demandas e fontes de água}

Os dados de usos, demandas e fontes de água foram obtidos através de entrevistas para cadastro de usuários. Entrevistas foram realizadas em todas as propriedades adjacentes ao leito do rio - havendo ou não uso da água da aluvião - e também com as famílias que moram próximas e fazem uso das águas da aluvião do trecho rio.

Para a realização das entrevistas foi desenvolvido um formulário de cadastro, este foi testado em campo e passou por revisões. A versão final usada no cadastro é composta de nove páginas: Página 1 - Dados gerais do usuário; Páginas 2 a 6 - Dados dos mananciais de captação (Rio ou riacho; Barragem, açude ou barreiro; Tanque de pedra; Águas subterrâneas; Nascente ou olho d'água); Página 7 - Dados para usuários fornecedores de água; Página 8 - Usos da água; Página 9 - Dados de aproveitamento de água de chuva.

Os dados dos cadastros realizados foram previamente analisados quanto a sua consistência. Em casos como de insuficiência de informações ou valores incoerentes, voltou-se a campo para checagem. Após validação os dados foram processados em planilha eletrônica.

\subsection{Estimativa do potencial explorável}

Na quantificação dos volumes armazenáveis nos depósitos aluviais alguns estudos hidrológicos são fundamentais. Para definição da constituição desses depósitos deve ser realizada uma campanha de sondagens, com amostragem do material para ensaios granulométricos. A porosidade, necessária na avaliação do potencial explorável, e a condutividade hidráulica, para entender o escoamento, são coeficientes hidrodinâmicos importantes na caracterização das aluviões. As dimensões do depósito podem ser obtidas pela delimitação da sua área superficial e das suas espessuras, estas podendo ser avaliadas através de sondagens (Costa, 1984).

Para a análise granulométrica foram escolhidos espaçadamente 3 pontos (Figura 2) e em cada ponto foram coletadas amostras em diferentes profundidades (Tabela 1). Os ensaios foram efetuados 
de acordo com as Normas NBR-6457 (Associação Brasileira de Normas Técnicas, 1986), Amostras de solo - Preparação para ensaios de compactação e ensaios de caracterização, e NBR-7181 (Associação Brasileira de Normas Técnicas, 1984), Solo - Análise granulométrica.

Tabela 1 - Coordenadas geográficas e profundidades amostradas.

\begin{tabular}{|c|c|c|c|}
\hline \multirow{2}{*}{ Ponto } & \multicolumn{2}{|c|}{ Coordenadas Geográficas } & \multirow{2}{*}{$\begin{array}{c}\text { Profundidades } \\
\text { Amostradas (m) }\end{array}$} \\
\hline & Latitude & Longitude & \\
\hline P1 & $7^{\circ} 57^{\prime} 59.48 ” S$ & $36^{\circ} 19^{\prime} 52.70^{\prime \prime} 0$ & $\begin{array}{c}\text { Superfície } \\
0,30 \\
0,60\end{array}$ \\
\hline P2 & $7^{\circ} 57^{\prime} 25.80^{\prime \prime S}$ & $36^{\circ} 18^{\prime} 30.78^{\prime \prime} 0$ & $\begin{array}{l}0,70 \\
3,00\end{array}$ \\
\hline P3 & 756'36.79”S & $36^{\circ} 17^{\prime} 31.82^{\prime \prime} 0$ & 3,80 \\
\hline
\end{tabular}

A tendência central da distribuição granulométrica foi obtida através da média gráfica (Equação 1), determinada pela média dos diâmetros $\mathrm{d}_{16}, \mathrm{~d}_{50}$ e $\mathrm{d}_{84}$, correspondentes aos diâmetros das peneiras onde passam 16\%, 50\% e 84\% da amostra, respectivamente (Folk \& Ward, 1957 citado por Pettijohn et al., 1987). Os valores de $d_{16}$, $d_{50}$ e d84, foram obtidos através de interpolação entre os pontos das curvas granulométricas de frequência acumulada.

$M z=\frac{d_{84}+d_{50}+d_{16}}{3}$

Para classificação das amostras utilizou-se os intervalos de tamanhos de grãos propostos por Pettijohn et al. (1987) e o grau de dispersão de tamanhos de grão foi classificado pelos parâmetros de coeficiente de uniformidade da ABNT (Associação Brasileira de Normas Técnicas, 1995), calculados pela Equação 2 (Custodio \& Llamas, 1976):

$f=\frac{d_{60}}{d_{10}}$

em que $f$ é coeficiente de uniformidade e $d_{60}$ e $d_{10}$ correspondem aos diâmetros das peneiras onde passam $60 \%$ e $10 \%$ da amostra, respectivamente. Os valores de $\mathrm{d}_{10}$ e $\mathrm{d}_{60}$ de cada amostra foram obtidos a partir de interpolação dos pontos das curvas granulométricas de frequência acumulada.

Devido à seca, os níveis d'água na aluvião se encontravam baixos, impossibilitando a determinação da condutividade hidráulica a partir de testes de aquífero, sendo esta então determinada pelos métodos BEST (Beerkan Estimation of Soil Transfer Parameters through Infiltration Experiments), desenvolvido por Lassabatère et al. (2006), e de Breddin (1963 citado por Custodio \& Llamas, 1976).

Foram realizados, de acordo com procedimentos indicados por Souza et al. (2008), testes de infiltração tridimensional, com carga positiva, em infiltrômetro de anel simples com 15 centímetros de diâmetro. Os pontos e profundidades dos testes foram os mesmos onde houve a coleta de amostra para a análise granulométrica. A partir dos testes de infiltração obteve-se os valores de entrada do modelo BEST.

A partir da condutividade hidráulica, a porosidade efetiva foi calculada utilizando as Equações 3 (Poulsen et al., 1999a) e 4 (Poulsen et al., 1999b):

$\varnothing_{e}=0,066137 K_{s}^{1 / 3,15 * \theta_{s}{ }^{2 / 3}}$

$\varnothing_{e}=10^{\left[\frac{\log K_{s}-4,3}{2,8}\right]}$

em que $\varnothing_{e}$ é a porosidade efetiva $\left(\mathrm{cm}^{3} / \mathrm{cm}^{3}\right), K_{s}$ é a condutividade hidráulica $\left(\mathrm{cm} /\right.$ dia) e $\theta_{s}$ é a umidade de saturação.

O contorno da área superficial da aluvião foi determinado pelo contraste de imagens via satélite, através das imagens do software Google Earth Pro 7.1. É um programa de gratuito, com uso 
experimental liberado mediante cadastro. As funcionalidades de geoprocessamento permitiram calcular áreas e volumes. Foi feita a checagem da coerência entre o contorno obtido através das imagens de satélite e das condições realmente existentes em campo e o registro de coordenadas geográficas através de aparelho GPS portátil.

Avaliando a precisão cartográfica do Google Earth a partir da comparação entre distância medidas em cartas cartográficas e nas imagens do programa, Lopes \& Nogueira (2011) encontraram erros médios de apenas 3,54\% para as áreas e 1,39\% para os perímetros. Menegatto Junior \& Ferreira (2013), utilizando imagens provenientes do Google Earth e mapas de hierarquia fluvial para a estimativa da largura de rios, concluíram que o método utilizado, baseado no uso de imagens do Google Earth para definição de larguras de rios, mostrou-se eficiente, mas alertaram que "a realização de trabalhos de campo para conferir a acurácia dos dados se faz necessária e essencial para a confirmação dos dados aferidos".

A espessura da camada aluvial foi determinada a partir da média entre as profundidades observadas nos poços amazonas - poços escavados para extração de água que possuem revestimento da sua parede (Vasconcelos, 2014), também chamados de cacimbões (Paiva et al., 2014), aqui não se fazendo diferenciação pelo seus diâmetros - do trecho estudado que atingiram o embasamento rochoso.

Para o cálculo da reserva de água explorável é necessário obter a parcela porosa diante do volume total, que pode ser obtido conforme a Equação 5 (Oliva et al., 2010):

$V_{e x p}=A^{*} b * \varnothing_{e, a v g}$

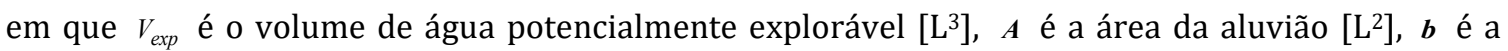
espessura de reservação de água média ou espessura saturada média [L] e $\varnothing_{\boldsymbol{e}, \text { avg }}$ é a porosidade efetiva média da aluvião.

\subsection{Balanço hídrico expedido de reserva versus demanda}

Para a determinação da demanda foram obtidos valores para os fins registrados no processo do Cadastro de Usuários. A partir de valores referenciados na literatura para cada atividade, foram obtidos os consumos diários e com a soma destes consumos obteve-se a estimativa da demanda diária total. 0 consumo humano per capita adotado foi de 150 L/dia (Heller \& Pádua, 2016).

O consumo de água na dessedentação em cada espécie vai depender de um conjunto de variáveis, como a raça, a idade do animal, o peso, se lactante, da temperatura, etc. Foram usados valores médios de ingestão para cada grupo de animais conforme com literatura específica (Araújo et al., 2011; Palhares, 2013). De acordo com Peden et al. (2018), a quantidade de água ingerida representa apenas $2 \%$ do total de água necessário para um animal. Está foi a relação utilizada para o cálculo do consumo total na criação animal.

Com a divisão da estimativa do volume explorável da aluvião pela demanda - soma dos consumos doméstico e produtivos - foi calculado o tempo em que, sem recarga, o aquífero aluvionar é capaz de abastecer o consumo.

\section{RESULTADOS E DISCUSSÃo}

\subsection{Características de usos das águas}

No trecho do rio estudado residem 143 habitantes, em quatro povoados (Morcego, Poço Comprido, Poço da Lama e Arapuá). Em três propriedades não há residentes fixos, uma indústria (lavanderia de jeans) e duas fazendas de criação de gado. Ao todo foram realizados 33 cadastros, com faixa de residentes de 0 a 13 pessoas.

Quanto às fontes de abastecimento (Figura 3), o uso preponderante é das águas oriundas da aluvião, seja por poços amazonas ou cacimbas - poços escavados sem paredes de revestimento (Vasconcelos, 2014). Em apenas uma propriedade não havia este uso, usando-se nela apenas um poço tubular através do embasamento cristalino.

Não houve registros de captação direta em rios ou riachos. Foi informado que esse procedimento só ocorre em curto período, logo após as chuvas que geram escoamento superficial no rio, o que é compreensível pelo regime temporário. 
Em todos os casos onde açude, barreiro ou barragem se constituía como uma das fontes de captação, a água da aluvião também é usada. Isso é justificado pois as altas taxas de evaporação fazem com que a água acumulada nas fontes superficiais, ainda que não seja esgotada pelo uso, evapore (Cirilo, 2008).

Apesar de toda a extensão da área de estudo ser transpassada longitudinalmente por uma adutora em forma de canal, não houve nenhum registro de abastecimento por rede pública. É uma situação similar aos levantamentos de mananciais de Mendonça et al. (2012) em comunidades realizadas no Sertão do Pajeú-PE, onde também não há registros de abastecimento por rede pública. Segundo o autor, a totalidade dos domicílios possuíam cisternas - na área aqui pesquisada isso ocorre em torno de $80 \%$ - e boa também usavam água de poços e de açudes.

Já os dados do Censo 2010 para o conjunto das comunidades rurais do Nordeste diferem bastante. Segundo os dados do IBGE, mais de um terço dos domicílios rurais do Nordeste são abastecidos por redes de distribuição, 38\% são abastecidos por poços e apenas 14\% através de cisternas (Landau et al., 2016). Os valores para Pernambuco (24\%, 33\% e 25\%, respectivamente) são mais próximos, mas ainda assim muito diferentes dos aqui registrados e dos apresentados por Mendonça et al. (2012). Duas conjecturas podem explicar essas distorções. Os dados do Censo são para áreas rurais de todo o Nordeste, e não apenas comunidades do Semiárido. E a existência de núcleos concentrados com estruturas de abastecimento e maior densidade populacional causa um distúrbio na média em relação a maioria das localidades.

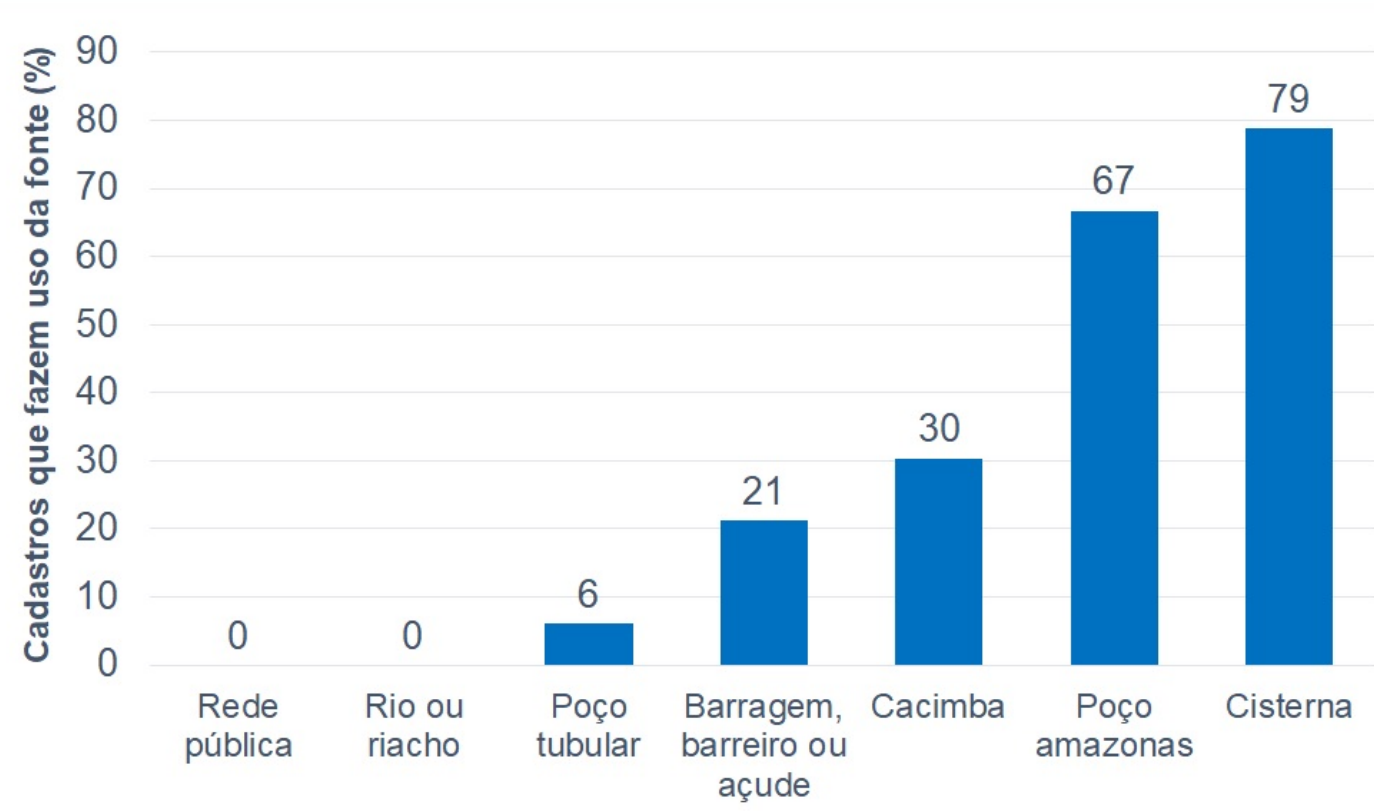

Tipos de abastecimento de água

Figura 3 - Percentagem de tipos de abastecimento usados

As finalidades de uso da água (Figura 4) podem ser divididas em três grandes grupos: atividades domésticas mais nobre (beber e preparar alimentos), atividades domésticas menos nobres (banho, lavagens, descarga sanitária) e atividades produtivas (criação animal e irrigação). Esses são os usos mais comuns. Além deles foram registrados dois usos pontuais, uma lavanderia industrial de produção de jeans e ponto de extração de água para venda em carros pipas.

A lavandeira de jeans usa água de um poço amazonas em seu processo industrial, mas não houve registro de descarte das águas residuárias no rio. Esta é uma prática que acontece em maior número em trechos mais a jusante do rio Capibaribe, à medida que este se aproxima da cidade de Toritama, impactando negativamente de forma muito significativa na qualidade da água (Melo et al., 2017).

A exportação de água da aluvião, através de carros pipas, para o abastecimento de zonas urbanas nos distritos e na cidade de Santa Cruz do Capibaribe é comum. A cidade de Santa Cruz do Capibaribe é abastecida prioritariamente pela barragem de Jucazinho, que estava totalmente em colapso desde 2016, só voltando a operar neste início de 2020. Nesse cenário, a água da aluvião foi umas das 
alternativas buscadas pela população da cidade, através de carros pipas. Esta atividade estava bastante diminuída no momento das entrevistas por conta dos baixos níveis d'água registrados na aluvião.

A água das cisternas é usada somente nas atividades domésticas, principalmente nas mais nobres. Nas menos nobres o que mais se usa é a água da aluvião. Em suas pesquisas Mendonça et al. (2012) não separam os usos domésticos, nos seus resultados as águas para consumo humano 58\% são oriundas de cisternas, $29 \%$ provenientes de açudes e $13 \%$ de poços.

Nas atividades de irrigação e criação animal a principal origem da água é a aluvião. Destaca-se que não foram encontradas cisternas do tipo calçadão, mesmo havendo ampla oferta de áreas nas propriedades e desejo entre os entrevistados de as possuir. Como ressaltam Ferreira et al. (2015), estas cisternas podem ser instrumentos importantes na produção de alimentos e da criação de animais em famílias de comunidades rurais do semiárido. Mendonça et al. (2012) também indicaram as águas de poços como as mais usadas nas atividades produtivas, mas registraram que cerca de $1 / 4$ das famílias usavam águas de cisternas de produção para este fim.

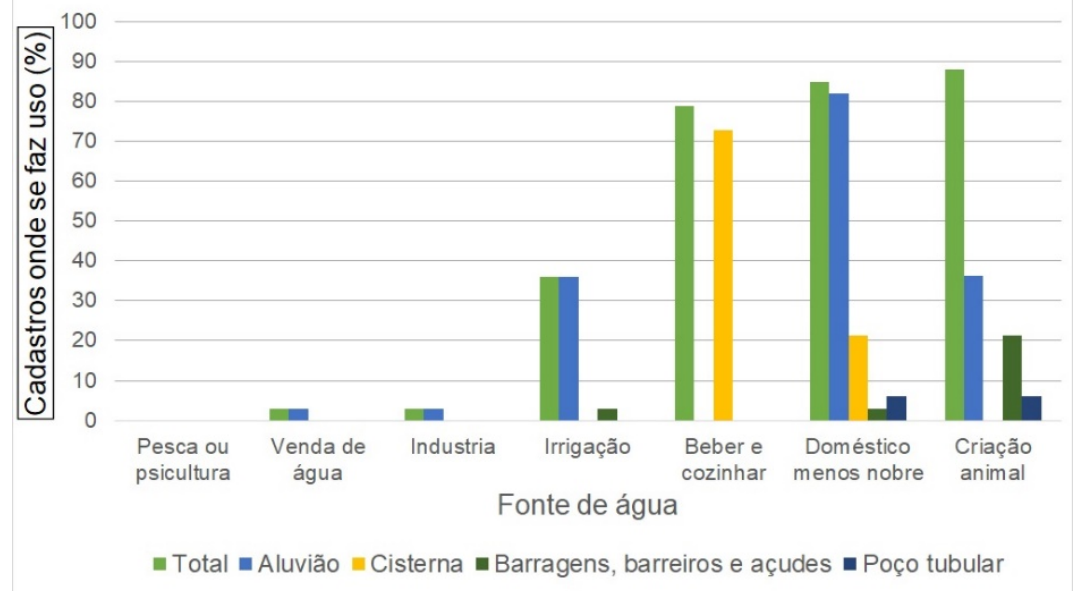

Figura 4 - Percentagem de cadastro por finalidade de uso e origem de água

A irrigação estava quase totalmente concentrada na produção de capim, sempre por aspersão. Segundo os entrevistados, com o prolongamento da seca diminuíram as áreas e a diversidade de culturas irrigadas. Na conjuntura de acentuada escassez hídrica, a intenção é garantir água para a criação animal. A quase totalidade da cultura irrigada sendo capim, utilizado como alimento para os animais, reforça essa atitude.

A criação animal é a principal atividade produtiva entre os entrevistados. Os recursos hídricos disponíveis, em destaque à água da aluvião, são bastante utilizados para este fim. Apesar de haver maior quantidade de casos (Figura 5) onde há a criação de bovinos, a maior população é a de caprinos.

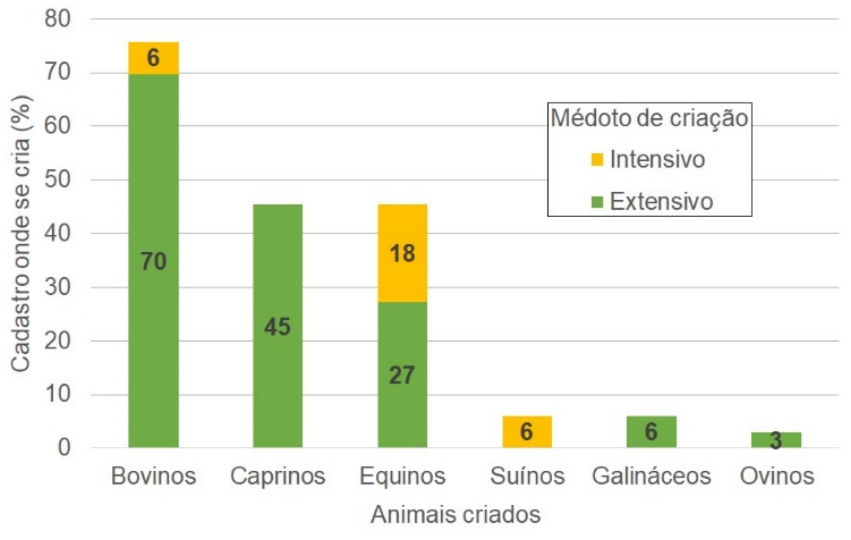

Figura 5 - Percentagem de cadastros por animais criados 


\section{Segurança hídrica}

Foi possível verificar que água oriunda da aluvião é a fonte mais segura e permanente nestas comunidades. Mendonça et al. (2012) também verificaram que nas localidades onde se usava água das aluviões, através de barragens subterrâneas, as práticas agrícolas eram incrementadas.

Apesar disso, com prolongamento da seca e o consequente rebaixamento dos níveis d'água, a maior parte dos usuários teve que diminuir e em alguns casos paralisar, as atividades produtivas. Parte das cacimbas havia sido escavadas recentemente, no atual período de seca, de maneira emergencial, na perspectiva de abastecer os próprios ribeirinhos e terceiros através de carros pipas.

Os poços amazonas têm profundidade média de 3,00 $\mathrm{m}$ com desvio padrão de 0,98 $\mathrm{m}$ e em média apresentaram lâmina de água de 0,30 $\mathrm{m}$ com desvio padrão de $0,16 \mathrm{~m}$ (Figura 6). As cacimbas tinham profundidade média também de 3,00 $\mathrm{m}$ com desvio padrão de 1,02 $\mathrm{m}$ e lâmina de água média de $0,52 \mathrm{~m}$ com desvio padrão de $0,26 \mathrm{~m}$. 0 que determina a profundidade escavada dos poços na aluvião é o nível da lâmina d'água, sendo assim escavados até ser possível atingi-la e captar a água no volume necessário. Com o prolongamento da seca os poços foram sendo aprofundados, alguns chegando até ao embasamento rochoso.

Analisando a diferença na profundidade em que se encontrava a lâmina de água nos poços, vê-se que há diferenças significativas, variando de menos de $1 \mathrm{~m}$ a mais de $4 \mathrm{~m}$ de profundidade até à presença da água. Um possível entendimento disso é que deve haver barramentos naturais funcionando como barragens subterrâneas em alguns pontos, impedindo o escoamento subsuperficial no sentido de equilíbrio da energia potencial da água na aluvião.

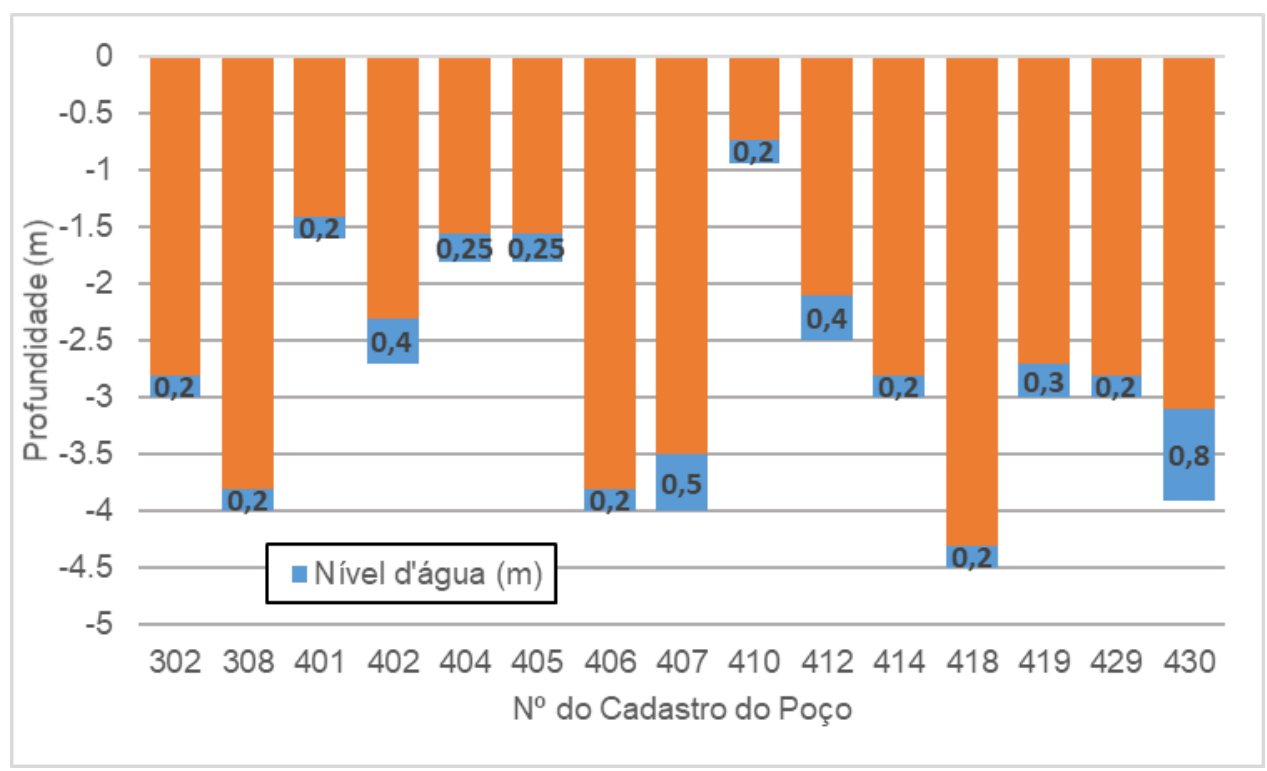

Figura 6 - Distribuição das profundidades dos poços amazonas

Nas cisternas a capacidade de armazenamento média é de 3,88 mil litros/hab. Considerando que a cisterna esteja cheia no final do período chuvoso, em julho, até o início do próximo período, em fevereiro, cada habitante terá disponível em média aproximadamente 650 litros de água por mês, em torno de 20 litros por dia. $20 \mathrm{~L} / \mathrm{hab} /$ dia é justamente o valor mínimo razoável definido pela Organização Mundial da Saúde (World Health Organization, 2000). Os dados obtidos evidenciam que, mesmo em anos onde a chuvas fiquem perto da média histórica, a água armazenada nas cisternas será suficiente apenas para o uso mais nobre em atividades domésticas.

Dos 26 casos onde existiam cisternas, 16 estavam sendo abastecidas por carros pipas. Destes 16, apenas duas recebiam água de programas governamentais (no caso, do exército), nos demais casos os moradores compravam a água. $\mathrm{O}$ abastecimento das cisternas com carros pipas também foi verificado por Mendonça et al. (2012), no momento das entrevistas, período de estiagem.

Em apenas um caso a cisterna não possuía estrutura de captação de água do telhado. Em $64 \%$ dos casos a capacidade de armazenamento é de até 16 mil litros, tamanho padrão da cisterna construída no "Programa Um Milhão de Cisternas". 
Em relação às barragens, barreiros e açudes, mais de dois terços estavam vazios ou muito próximos do esvaziamento. Além disso, outro problema desse tipo de mananciais é que geralmente estão a distâncias bem maiores dos locais de uso da água.

Gomes \& Heller (2016), em levantamento em domicílios rurais no semiárido mineiro, concluem que as cisternas são importantes, mas não suprem sozinhas a demanda de água e que é necessário o uso combinado de diferentes técnicas. A análise geral dos dados corrobora com isto, e reafirma o discutido por Araújo, Ribeiro \& Reis (2010), no sentido de que nenhuma tecnologia isolada resolverá plenamente, em quantidade e qualidade, o problema de escassez de água para uso doméstico e para produção.

\subsection{Caracterização da camada aluvial}

As curvas granulométricas de frequência acumulada geradas a partir das análises realizadas (Figura 7) têm comportamento semelhante. A superfície do ponto P1 é a que difere mais, tendo uma porcentagem maior, próxima a 50\%, de partículas com diâmetro de até 0,01 mm, o que já era esperado pelo fato de as camadas superficiais em geral terem um maior teor de finos, inclusive de matéria orgânica.

Quanto à uniformidade (Tabela 2), excetuando-se a amostra P1 superficial, que apresenta uma grande desuniformidade, as amostras são medianamente uniformes. As amostras mais profundas, P2 na profundidade 3,00 m e P3 na profundidade 3,80 m, apresentam mais uniformidade, estando bem próximas do limite de classificação como uniforme (5) da ABNT (Associação Brasileira de Normas Técnicas, 1995).

Essa classificação vai ao encontro dos resultados de Rodrigues (2012), que analisando 23 amostras em um vale aluvial de rio intermitente do semiárido pernambucano classificou 18 delas como medianamente uniformes, três como desuniformes e duas como uniformes.

O coeficiente de uniformidade vai impactar diretamente no grau de representatividade dos valores médios tomados para representar cada amostra. Trivialmente é possível se entender que quanto maior for o grau de uniformidade, mais o valor médio tente a ser representativo do todo da amostra.

A tendência central da distribuição granulométrica, expressa pela média gráfica, indica que a fração mais abundante em todas as amostras, como era de se esperar, é de areia. Os resultados variam de 0,253 (areia média) a 0,651 (areia grossa). Chama a atenção a amostra da superfície do ponto P1, que mesmo tendo uma porcentagem maior passando nas peneiras até $0,01 \mathrm{~mm}$, pela média gráfica é classificada com areia grossa.

A distribuição granular realizada por Brito et al. (2018) em um ponto dentro da área de estudo deste trabalho verificou que a porcentagem de areia nos sedimentos é superior a 70\%. Também na mesma área, Alves et al. (2020) analisaram duas amostras que continham 79\% e 95\% de areia e as classificaram como areia argilosa e areia, respectivamente.

A classificação das amostras como de areia média a areia grossa difere um pouco dos valores encontrados em Rodrigues (2012), que no estudo de um vale aluvial classificou a maioria das amostras como areias finas e médias. Dados do projeto PROALUV do Serviço Geológico Brasileiro, com 2761 furos de perfis litológicos em aluviões, expressaram uma composição média de 64\% de areia, $30 \%$ de argila e $7 \%$ de silte (Peixinho et al., 2009).

Os valores e a classificação em areia de média a grossa confirmam uma impressão visual que pode ser observada na aluvião na área da pesquisa. Essa classe de solos tende a ser mais propícia para a acumulação e extração de água da aluvião, com melhor porosidade e condutividade hidráulica para este fim.

A condutividade hidráulica foi inicialmente determinada a partir do método BEST (Lassabatère et al., 2006). A aplicação do método de Beerkan só foi possível nas amostras P2 0,70 m e P3 3,80 m. 0 tempo de infiltração muito rápido impossibilitou a aplicação do método nos demais casos.

$\mathrm{Na}$ impossibilidade de obter-se as condutividades hidráulicas diretamente a partir dos testes realizados, optou-se como alternativa a determinação indireta da condutividade pelo método de Breddin (Breddin, 1963 citado por Custodio \& Llamas, 1976).

Excetuando-se a curva da Amostra P1 superficial, as demais curvas têm sua maior parte quase que totalmente compreendida nas faixas 5 e 6 (Figura 7). Todas as curvas ocuparam mais de uma classe de Breddin. Na determinação da condutividade hidráulica de cada curva foi levado em conta o tamanho do intervalo em que a curva está presente em cada faixa, proporcionalmente. 


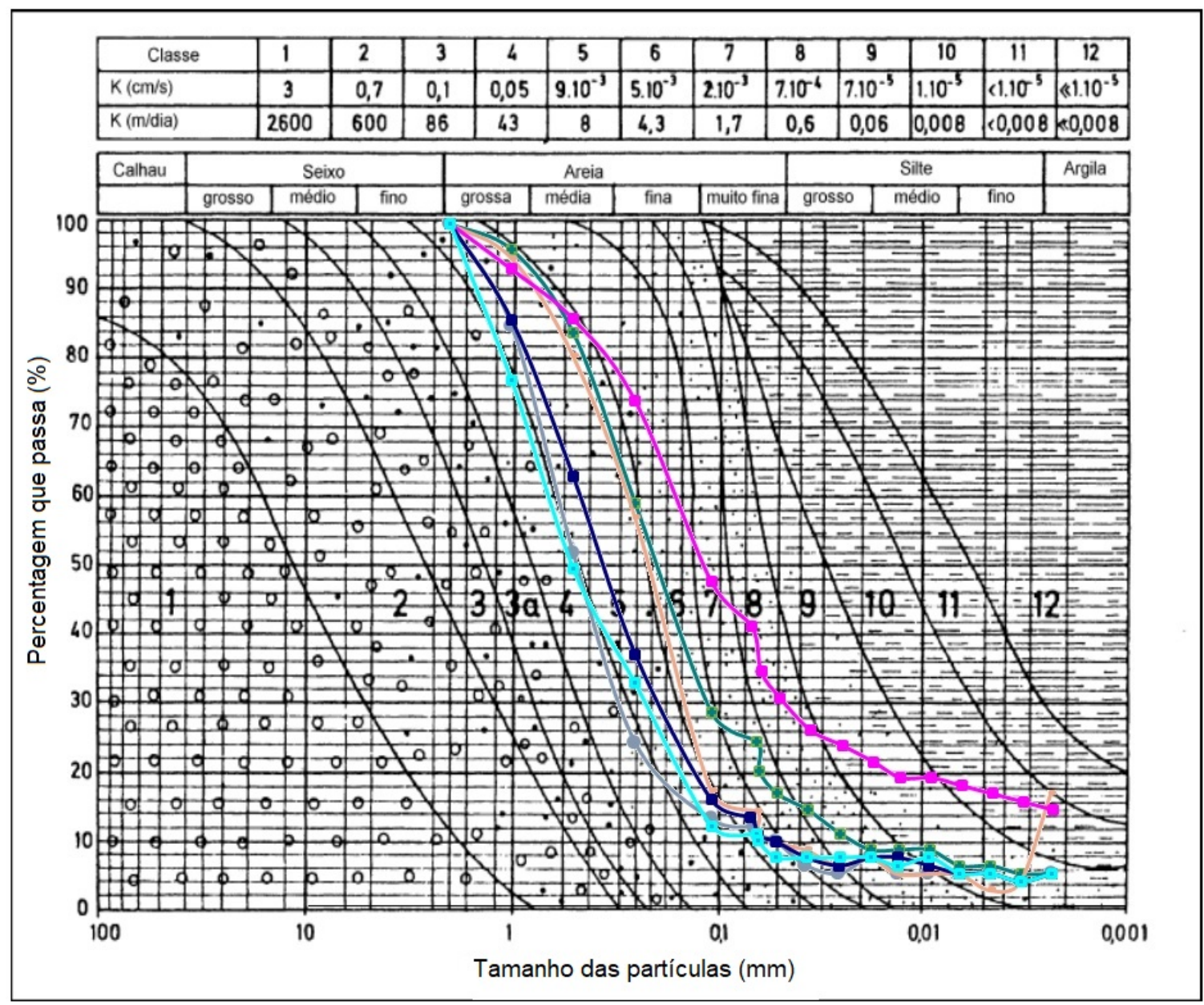

Figura 7 - Curvas granulométricas plotadas nas classes de Breddin. Adaptado de Custodio \& Llamas (1976).

Os valores de condutividade hidráulica (Tabela 2) variam de $10^{-5}$ a $10^{-4} \mathrm{~m} / \mathrm{s}$. Esses valores podem ser considerados bem coerentes. Fetter (1988) afirma que areias bem selecionadas apresentam condutividade hidráulica na faixa de $10^{-5}$ a $10^{-3} \mathrm{~m} / \mathrm{s}$. Em comparação aos valores determinados pelo método de Beerkan, os valores encontrados para P2 0,70 m e para P3 3,80 m apresentam valores na mesma ordem de grandeza para cada amostra, $10^{-5}$ e $10^{-4} \mathrm{~m} / \mathrm{s}$, respectivamente, sendo que para P2 0,70 m foi encontrado o mesmo valor, $0,06 \mathrm{~mm} / \mathrm{s}$.

Silva (2015), através de equações empíricas, obteve resultados entre $10^{-4}$ e $10^{-3} \mathrm{~m} / \mathrm{s}$ para estudos realizados na mesma área deste trabalho. Também nessa área de estudo, Vasconcelos (2015), utilizando a metodologia de Beerkan, caracterizou as camadas de aluvião com condutividade hidráulica variando na faixa entre $10^{-6}$ a $10^{-3} \mathrm{~m} / \mathrm{s}$ e valores médios de $0,75 \mathrm{~mm} / \mathrm{s}$ e $0,27 \mathrm{~mm} / \mathrm{s}$ nas duas áreas por ela amostradas. Esses valores, em especial os valores médios determinados por Vasconcelos (2015), são bem próximos e coerentes com os aqui calculados.

Não foi possível o cálculo da porosidade através da equação de Poulsen et al. (1999a) nas amostras onde a utilização do método de Beerkan não foi viável, porque a expressão necessita da variável $\theta_{\mathrm{s}}$ (umidade de saturação), que é um dos parâmetros obtidos através deste método.

Para as duas amostras, em que a porosidade foi determinada também pela equação de Poulsen et al. (1999a), é possível observar (Tabela 2) que os valores calculados são muito próximos dos determinados pela equação de Poulsen et al. (1999b).

0 valor médio encontrado demonstra uma camada aluvial com uma porosidade muito propicia para a acumulação de água. Rodrigues (2012), usando a equação de Poulsen et al. (1999b) para uma aluvião em outra localidade do semiárido pernambucano, encontrou o valor médio de 15,5\%, bem abaixo dos valores aqui determinados. Vasconcelos (2015) em sua pesquisa realizada na mesma aluvião da pesquisa aqui apresentada, determinou, pelo método de Beerkan, valores de porosidade total variando de $41,48 \%$ a $49,47 \%$. Silva (2015) também nesta mesma região de estudo obteve uma porosidade de $46 \%$. 
Tabela 2 - Valores calculados da análise granulométrica da aluvião.

\begin{tabular}{|c|c|c|c|c|c|c|c|c|}
\hline \multirow[b]{2}{*}{ Amostra } & \multicolumn{2}{|c|}{$\begin{array}{l}\text { Coeficiente de } \\
\text { uniformidade }\end{array}$} & \multicolumn{2}{|c|}{ Média gráfica } & \multicolumn{2}{|c|}{$\begin{array}{l}\text { K - Condutividade } \\
\text { hidráulica }(\mathrm{mm} / \mathrm{s})\end{array}$} & \multicolumn{2}{|c|}{ Porosidade efetiva } \\
\hline & $f$ & $\begin{array}{c}\text { Classificação } \\
\text { (Associação } \\
\text { Brasileira de } \\
\text { Normas } \\
\text { Técnicas, 1995) }\end{array}$ & $\mathbf{M}_{\mathbf{z}}$ & $\begin{array}{c}\text { Classe } \\
\text { granulométrica }\end{array}$ & $\begin{array}{l}\text { Método } \\
\text { de } \\
\text { Beerkan }\end{array}$ & $\begin{array}{l}\text { Método } \\
\text { de } \\
\text { Breedin }\end{array}$ & $\begin{array}{c}\Phi_{\mathrm{e}}= \\
0,066137^{*} \\
\mathrm{~K} 1 / 3,15 * \theta \mathbf{s}^{2 / 3}\end{array}$ & $\begin{array}{c}\Phi_{\mathrm{e}}= \\
10[(\log \mathrm{K}- \\
4,3) / 2,8]\end{array}$ \\
\hline P1 sup. & 75,12 & Desuniforme & 0,587 & Areia Grossa & $x$ & 0,03 & - & $21,98 \%$ \\
\hline $\mathrm{P} 10,30 \mathrm{~m}$ & 8,02 & $\begin{array}{l}\text { Medianamente } \\
\text { uniforme }\end{array}$ & 0,535 & Areia Grossa & $\mathrm{x}$ & 0,08 & - & $30,12 \%$ \\
\hline $\mathrm{P} 10,60 \mathrm{~m}$ & 12,24 & $\begin{array}{l}\text { Medianamente } \\
\text { uniforme }\end{array}$ & 0,651 & Areia Grossa & $\mathrm{x}$ & 0,27 & - & $46,26 \%$ \\
\hline P2 0,70m & 11,09 & $\begin{array}{l}\text { Medianamente } \\
\text { uniforme }\end{array}$ & 0,253 & Areia Média & 0,06 & 0,06 & $26,22 \%$ & $26,52 \%$ \\
\hline P2 3,00m & 5,06 & $\begin{array}{l}\text { Medianamente } \\
\text { uniforme }\end{array}$ & 0,313 & Areia Média & $\mathrm{x}$ & 0,06 & - & $27,87 \%$ \\
\hline \multirow[t]{2}{*}{ P3 3,80m } & 5,36 & $\begin{array}{l}\text { Medianamente } \\
\text { uniforme }\end{array}$ & 0,540 & Areia Grossa & 0,31 & 0,19 & $41,26 \%$ & $40,87 \%$ \\
\hline & & & & Média & $\mathrm{x}$ & 0,11 & $33,74 \%$ & $34,24 \%$ \\
\hline
\end{tabular}

\subsection{Estimativa do potencial explorável de água nas aluviões}

$\mathrm{Na}$ perspectiva de obter melhor delimitação, foram usadas imagens de diferentes datas de aquisição. Assim, foi possível obter-se para cada trecho a imagem mais nítida, descartando o uso das que apresentassem problemas, como nuvens, dificultando a visualização da superfície.

0 valor obtido foi de $346.196 \mathrm{~m}^{2}$. Considerando que o trecho tem um comprimento longitudinal de aproximadamente $8.340 \mathrm{~m}$, tem-se uma largura média da aluvião de 41,50 m.

A espessura da aluvião foi determinada a partir da profundidade dos poços amazonas do trecho. Com a rebaixamento do nível d'água na aluvião pelo prolongamento da seca, vários poços foram aprofundados até o embasamento rochoso, ou muito próximo a isso. 0 valor considerado foi a média entre essas profundidades dos poços, sendo calculado o valor de 3,61 m.

Para determinação da espessura da aluvião que é explorada, precisa-se definir, dentro da espessura total da camada aluvial, os limites inferior e superior de acumulação de água para explotação.

Como limite inferior foi considerado o próprio embasamento rochoso. Essa consideração foi adotada assumindo a profundidade dos poços amazonas, pois boa parte dos poços já atinge esse limite.

A definição do limite superior é menos trivial. Uma possibilidade seria a observação dos níveis da água na aluvião após um período chuvoso regular. Como todo o desenvolvimento desta pesquisa se deu em um cenário de seca prolongada, esta opção tornou-se inviável.

Para determinação do limite superior foi levada em consideração a espessura da aluvião necessária para reduzir ao mínimo as perdas por evaporação na camada de aluvião. A partir deste ponto estará a água "reservada" para a explotação. A partir dos dados de Araújo Filho et al. (2016), que pesquisaram a influência da camada de areia na proteção do efeito da evaporação da água armazenada na aluvião, foi adotado o valor de 0,5 m. Assim, a espessura média explorável da aluvião é de $3,11 \mathrm{~m}$.

A partir dos valores de porosidade efetiva média $\left(\varnothing_{\mathrm{e}, \mathrm{avg}}\right)$, da área da superfície da aluvião (A) e da espessura saturada média (b), foi possível obter-se o volume de água potencialmente explorável ( $\left.V_{\exp }\right)$ pela Equação 5.

0 valor calculado foi da ordem de $900 \mathrm{mil} \mathrm{m}^{3}$. Trata-se de uma reserva potencial de aproximadamente $100 \mathrm{~m}^{3} / \mathrm{m}$ no sentido longitudinal do trecho. Silva (2015) estimando o potencial de acumulação de água na aluvião do mesmo trecho, chegou ao valor de $69 \mathrm{~m}^{3}$ para cada metro de extensão longitudinal do trecho. No seu cálculo, Silva (2015) considerou uma largura de 50 m (a menor entre as três seções por ele levantadas), espessura de 3 m e 46\% de porosidade. Por isso registra-se a diferença no valor calculado.

\subsection{Balanço hídrico de reserva versus demanda}

O estabelecimento de qual é a real demanda de água pelos residentes dos povoados da região estudada é uma tarefa de difícil solução exata. As dificuldades advêm de diferentes fatores. Por exemplo, em geral, não são as atividades desenvolvidas que estabelecem um determinado 
consumo como demanda de água, e sim a quantidade de água disponível é que estabelece as atividades, e em que grau.

Também a quantificação do que é consumido pelas famílias nas suas atividades torna-se difícil porque, em geral, o consumo não é feito de forma regular e, menos ainda, medido. Aqui o consumo médio foi estabelecido por valores da literatura para as atividades desenvolvidas. Assim, com uma população residente de 143 habitantes, tem-se um consumo diário de $21.450 \mathrm{~L}$.

0 cadastro de usuários mostrou que no momento da pesquisa a demanda de água para atividades produtivas estava concentrada na criação animal, seja diretamente na dessedentação, seja em atividades como a irrigação de capim para alimentar os animais. Levando isto em consideração, a quantificação da demanda produtiva foi realizada para a criação animal (Tabela 3).

Tabela 3 - Demanda diária de água total por espécie animal.

\begin{tabular}{c|c|c|c}
\hline \multirow{2}{*}{ Animal } & $\begin{array}{c}\text { Consumo per capita } \\
\text { (L/dia) }\end{array}$ & População & $\begin{array}{c}\text { Consumo diário total } \\
\text { (L) }\end{array}$ \\
\hline Bovinos & 40 & 422 & 16880 \\
\hline Suínos & 8 & 22 & 176 \\
\hline Caprinos e Ovinos & 3 & 760 & 2280 \\
\hline Galináceos & 0,250 & 35 & 8,75 \\
\hline Equinos & 45 & 73 & 3285 \\
\hline \multicolumn{2}{r|}{} & Total & 22630 \\
\cline { 2 - 4 } & &
\end{tabular}

Com para a ingestão, foi calculado um valor total de consumo de água diário na criação animal de 1.131.488 L.

Somando o valor para a criação animal com o valor para consumo humano, chega-se a um consumo total diário de $1152 \mathrm{~m}^{3}$. Comparando este valor com a reserva estimada da aluvião, o resultado é que a reserva pode suportar, sem recarga, este consumo por 2,14 anos.

É importante ressaltar que todos os valores aqui obtidos se relacionam com um cenário onde o desenvolvimento de atividades de agricultura e pecuária está diminuído pela escassez de água provocada por uma seca prolongada. Também a condição de explotação da reserva está limitada pela disposição geográfica, profundidade e eficiência dos poços na captação da água.

\section{CONCLUSÕES}

Pelo seu volume, relativa facilidade de acesso e proteção natural contra a evaporação, a água armazenada na aluvião é o principal manancial de abastecimento de povoados rurais próximos a rios intermitentes do semiárido brasileiro. A pesquisa mostrou que este é um manancial usado pela quase totalidade da população local, sendo também, para a imensa maioria, o que proporciona a maior e mais regular oferta.

A população já possui propensão a usar água de diferentes fontes de forma combinada. Isto reforça a convicção de que o enfretamento da escassez de água no semiárido não deve ter solução única, e que melhores resultados advêm do uso combinado de alternativas.

Quem usa tecnologias de acumulação de água como barreiros e açudes tende a necessitar do uso de outras fontes para complementar o abastecimento, principalmente da água presente em aluvião.

A água armazenada nas cisternas é usada quase que exclusivamente para beber e cozinhar e esta é a fonte mais usada para estes fins. Por outro lado, a água da aluvião é a usada primordialmente nas atividades domésticas menos nobres, como banhos e limpeza da casa, e nas atividades agrícolas e pecuárias.

No cenário de seca foi priorizado, em termos produtivos, a água para a criação animal. Isso ficou claro tanto no uso da água diretamente para dessedentação animal, como na irrigação quase exclusiva de capim para alimentar os animais.

Os sedimentos aluviais do trecho do rio podem ser caracterizados como areias de médias a grossas, assim possuindo porosidade alta, sendo então as aluviões muito propícias para a acumulação de água.

A metodologia usando o ábaco de Breddin para estimativa dos parâmetros hidrodinâmicos levou aos resultados esperados. Este método se configura como alternativa importante em cenários onde, 
pelos níveis de água reduzidos e pela alta velocidade de infiltração, outros métodos têm seus usos dificultados.

Em um cenário de seca de elevada magnitude, o acesso a água ficou limitado, mas ainda assim foi possível manter os usuários razoavelmente atendidos graças às condições locais de armazenamento e captação de água em cisternas e, principalmente, a rede de poços na aluvião. Em anos de escassez menos rigorosa a potencialização da disponibilidade e o uso equilibrado destes recursos - sabendo em que magnitude, com qual finalidade e em quem momento usar cada manancial - pode garantir boa oferta de água, nas condições do semiárido onde ocorrem os depósitos aluviais para suprir as populações rurais difusas.

\section{AGRADECIMENTOS}

Os autores agradecem à Associação Águas do Nordeste pela colaboração e organização na experiência obtida no projeto Águas de Areias, à Petrobras Ambiental por ter patrocinado o referido projeto e a Fundação de Amparo à Ciência e Tecnologia do Estado de Pernambuco pela concessão de bolsa de mestrado. Os autores agradecem ainda as contribuições para o aprimoramento do artigo feitas pelos revisores e editores da REGA.

\section{REFERÊNCIAS}

Agência Pernambucana de Águas e Clima - APAC. (2018). Recuperado em 15 de janeiro de 2018, de http://www.apac.pe.gov.br/meteorologia/acum_mensal_old.php

Alves, A. T. A., Silva, L. T. M. S., Alcântara, L. R. P., Barros, V. H. O., Santos Neto, S. M., Lima, V. F., Lima, J. R. S., Coutinho, A. P., \& Antonino, A. C. D. (2020). Sorption of Remazol Black B dye in alluvial soils of the Capibaribe River Basin, Pernambuco, Brazil. Revista Ambiente e Agua, 15(2), e2491.

Araújo Filho, P. F., Cabral, J. J. S. P., \& Silva, A. V. (2016). Processo de evaporação no leito do rio seco. In R. A. P. Braga (Org.), Águas de Areias (pp. 71-88). Recife: Clã.

Araújo, G. G. L., Voltolini, T. V., Turco, S. H. N., \& Pereira, L. G. R. (2011). A água nos sistemas de produção de caprinos e ovinos. In T. V. Voltolini (Org.), Produção de caprinos e ovinos no Semiárido (pp. 69-94). Petrolina: Embrapa Semiárido.

Araújo, V. M., Ribeiro, E. M. R., \& Reis, R. P. (2010). Águas no rural do semiárido mineiro: uma análise das iniciativas para regularizar o abastecimento em Januária. Organizações Rurais \& Agroindustriais, 12(2), 219-233.

Associação Brasileira de Normas Técnicas - ABNT. (1984). NBR 7181 - Solo - Análise Granulométrica. Rio de Janeiro: ABNT.

Associação Brasileira de Normas Técnicas - ABNT. (1986). NBR 6457: Solo - Amostras de solo - preparação para ensaios de compactação e ensaios de caracterização. Rio de Janeiro: ABNT.

Associação Brasileira de Normas Técnicas - ABNT. (1995). NBR6502 - Rochas e solos. Rio de Janeiro: ABNT.

Braga, R. A. P., Farias, C. R. O., Silva, S. R., \& Cavalcanti, E. R. (2015). Gestão e educação socioambiental na bacia do Capibaribe (144 p.). Recife: Clã.

Brito, G. L. M. B., Coutinho, A. P., Cabral, J. J. S. P., Santos Neto, S. M., Antonino, A. C. D., Cirilo, J. A., Braga, R. A. P., \& Silva Filho, S. L. (2018). Characterization of the Capibaribe River Dry Bed with Ground Penetrating Radar (GPR). Revista Brasileira de Recursos Hídricos, 23, e1.

Cabral, J. J. S. P., Paiva, A. L. R., Araújo Filho, P. F., Vasconcelos, G. L. M. B., \& Silva, D. J., \& Coutinho, A. P. (2016). Acumulação de sedimentos e água no leito seco dos Rios no Semiárido. In R. A. P. Braga (Org.), Águas de Areias (pp. 39-70). Recife: Clã.

Cirilo, J. A. (2008). Políticas públicas de recursos hídricos para o semi-árido. Estudos Avançados, 22(63), 61-82.

Cirilo, J. A., Montenegro, S. M. G. L., \& Campos, J. N. B. (2010). A questão da água no semiárido brasileiro. In C. E. M. Bicudo, J. G. Tundisi, \& M. C. B. Scheuenstuhl (Orgs.), Águas do Brasil: análises estratégicas (Vol. 1, pp. 81-91). São Paulo: Instituto de Botânica.

Costa, W. D. (1984). Aquíferos aluviais como suporte agropecuário no Nordeste. In Anais do $3^{\circ}$ Congresso Brasileiro de Águas Subterrâneas (pp. 431-441). São Paulo: Associação Brasileira de Águas Subterrâneas.

Cunha, A. P. M. A., Zeri, M., Leal, K. D., Costa, L., Cuartas, L. A., Marengo, J. A., Tomasella, J., Vieira, R. M., Barbosa, A. A., Cunningham, C., Cal Garcia, J. V., Broedel, E., Alvalá, R., \& Ribeiro-Neto, G. (2019). Extreme drought events over Brazil from 2011 to 2019. Atmosphere, 10, 642. 
Custodio, E., \& Llamas, M. R. (1976). Hidrologia subterrânea. Barcelona: Ediciones Omega S.A.

Ferreira, E. P., Brito, L. T. L., Cavalcanti, N. B., \& Rolim Neto, F. C. (2015). Cisternas de produção para melhoria da qualidade de vida no Semiárido do estado de Pernambuco. Revista Verde de Agroecologia e Desenvolvimento Sustentável, 10, 13 19.

Fetter, C. W. (1988). Applied hydrogeology (2nd ed.). New York: Macmillan Publishing.

Gomes, U. A. F., \& Heller, L. (2016). Acesso à água proporcionado pelo Programa de Formação e Mobilização Social para Convivência com o Semiárido: um Milhão de Cisternas Rurais: combate à seca ou ruptura da vulnerabilidade? Engenharia Sanitaria e Ambiental, 21, 623-633.

Gutiérrez, A. P. A., Engle, N. L., De Nys, E., Molejon, C., \& Martins, E. S. (2014). Drought preparedness in Brazil. Weather and Climate Extremes, 3, 95-106.

Heller, L., \& Pádua, V. L. (2016). Abastecimento de água para o consumo humano. Belo Horizonte: Editora UFMG.

Landau, E. C., Moura, L., \& Luz, W. V. (2016). Abastecimento de água nos domicílios urbanos e rurais do Brasil em 201. In E. C. Landau, \& L. Moura (Orgs.), Variação geográfica do saneamento básico no Brasil em 2010: domicilios urbanose rurais (Vol. 1, pp. 37-74). Brasília, DF: Embrapa.

Lassabatère, L., Angulo-Jaramillo, R., Soria, J. M., Cuenca, R., Braud, I., \& Haverkamp, R. (2006). Beerkan Estimation of Soil Transfer parameters through infiltration experiments - BEST. Soil Science Society of American Journal, 70, 521-532.

Lopes, E. E., \& Nogueira, R. E. (2011). Proposta metodológica para validação de imagens de alta resolução do Google Earth para produção de mapas. In Anais do $10^{\circ}$ Simpósio Brasileiro de Sensoriamento Remoto. São José dos Campos: INPE.

Marengo, J. A., Cunha, A. P., \& Alves, L. M. (2016). A seca de 2012-15 no semiárido do Nordeste do Brasil no contexto histórico. Revista Climanálise., 3, 49-54.

Medeiros, S. A., Cavalcante, A. M. B., Marin, A. M. P., Tinôco, L. B. M., Salcedo, I. H., \& Pinto, T. F. (2012). Sinopse do censo demográfico para o semiárido brasileiro (103p.). Campina Grande: INSA.

Melo, R. R. C., Barbosa, I. M. B. R., Ferreira, A. A., Firmo, A. L. B., Silva, S. R., Cirilo, J. A., \& Aquino, R. R. B. (2017). Influence of extreme strength in water quality of the Jucazinho Reservoir, Northeastern Brazil, PE. Water, 9(12), 955.

Mendonça, Z. C. L., Candeias, A. L. B., Selva, V. F., Silva, M. M., Rodrigues, G. G., \& Santos, S. M. (2012). Aspectos sanitários e de uso da água em pequenas comunidades rurais do Semiárido Pernambucano. Revista Brasileira de Geografia Física, 5, 1191-1202.

Menegatto Junior, E. A., \& Ferreira, M. C. (2013). Estimativa de largura de rios, a partir de imagens do Google Earth e mapas de hierarquia fluvial, para o mapeamento de Áreas de Preservação Permanente na alta bacia do rio Jaguari, MG. In Anais do $16^{\circ}$ Simpósio Brasileiro de Sensoriamento Remoto (pp. 1258-1265). São José dos Campos: INPE.

Moura, M. S. B., Galvincio, J. D., Brito, L. T. L., Souza, L. S. B., Sá, I. I. S., \& Silva, T. G. E. (2007). Clima e Água de Chuva no Semiárido. In EMPRAPA Semiárido. Potencialidades da água de chuva no Semi-Árido brasileiro (pp. 37-59). Petrolina: Embrapa Semiárido.

Oliva, A., Kiang, C. H., \& Seixas, W. (2010). Cálculo de reservas hídricas subterrâneas do aquífero Rio Claro utilizando simulação Monte Carlo. Águas Subterrâneas, 24(1), 13-30.

Paiva, A. L. R., Caetano, T. O., Silva, D. J., Cabral, J. J. S. P., \& Braga, R. A. P. (2014). Ocorrência e características construtivas de poços escavados em aluvião - trecho alto rio Capibaribe - PE. In Anais do $12^{\circ}$ Simpósio de Recursos Hídricos do Nordeste. Porto Alegre: Associação Brasileira de Recursos Hídricos.

Palhares, J. C. P. (2013). Consumo de água na produção animal (Comunicado Técnico, No. 102). São Carlos: EMBRAPA.

Peden, D., Tadesse, G., \& Misra, A. K. (2018). Water and livestock form human development. Recuperado em 4 de janeiro de 2018, de http://www.iwmi.cgiar.org/assessment/Water\%20for\%20Food\%20Water\%20for\%20Life/Chapters/Chapter\%2 013\%20Livestock.pdf

Peixinho, F. C., Santos, L. C. A., Feitosa, F. A. C., Guerra, S. M. S., \& Silva, J. C. (Coords.). (2009). Caracterização regional e difusão tecnológica para uso sustentável dos recursos hídricos das aluviões do semiárido brasileiro (45р.). CPRM.

Pernambuco. Secretaria de Recursos Hídricos e Energéticos. (2010). Plano Hidroambiental da Bacia Hidrográfica do rio Capibaribe (PHA - Capibaribe). Recife: Secretaria de Recursos Hídricos e Energéticos.

Pernambuco. Ministério da Integração Nacional. Superintendência de Desenvolvimento do Nordeste - SUDENE. (2017a, 27 de julho). Resolução no 107/2017. Estabelece critérios técnicos e científicos para delimitação do Semiárido Brasileiro e procedimentos para revisão de sua abrangência. Diário Oficial do Estado de Pernambuco, Recife. Recuperado em 21 de janeiro de 2020, de http://sudene.gov.br/images/2017/arquivos/Resolucao-107-2017.pdf 
Pernambuco. Ministério da Integração Nacional. Superintendência de Desenvolvimento do Nordeste - SUDENE. (2017b, 22 de novembro). Proposição no 113/2017. Proposta de acréscimo da relação de municípios do Semiárido, com base em procedimento revisional decorrente de recursos interpostos por Estados da área de atuação da SUDENE sob o amparo da Resolução CONDEL no 107, de 27 de julho de 2017. Diário Oficial do Estado de Pernambuco, Recife. Recuperado em 21 de janeiro de 2020, de http://sudene.gov.br/images/arquivos/conselhodeliberativo/documentos/proposicao1132017.pdf

Pernambuco. Ministério de Desenvolvimento Regional. Superintendência de Desenvolvimento do Nordeste - SUDENE. (2020). Delimitação do Semiárido. Recuperado em 21 de janeiro de 2020, de http://www.sudene.gov.br/delimitacao-do-semiarido

Pettijohn, F. J., Potter, P. E., \& Siever, R. (1987). Sand and sandstone (553 p.). New York: Springer-Verlag.

Poulsen, T. G., Moldrup, P., Yamaguchi, T., Schjonning, P., \& Hansen, J. A. (1999a). Predicting soil-water ans soil-air transport properties and their effects on soil vapor extraction efficiency. Ground Water Monitoring Review, 19, 61-69.

Poulsen, T. G., Moldrup, P., Yamaguchi, T., \& Jacobsen, O. H. (1999b). Predicting saturated and unsaturated hydraulic conductivity in undisturbed soils from soil water characteristics. Soil Science, 164(2), 877-887.

Rodrigues, F. B. (2012). Caracterização Hidrogeológica de depósito aluvial do Riacho Boa Vista no Sítio Caiçara, Afogados da Ingazeira, PE (Dissertação de mestrado). Programa de Pós-Graduação em Geociências, Centro de Tecnologia e Geociências, Universidade Federal de Pernambuco, Recife.

Silva, A. C. S., Galvão, C. O., \& Silva, G. N. S. (2015). Droughts and governance impacts on water scarcity: an analysis in the Brazilian semi-arid. Proceedings of the International Association of Hydrological Sciences, 369, 129-134.

Silva, D. J. (2015). Caracterização da aluvião no alto rio Capibaribe (Trabalho de conclusão de curso). Centro Acadêmico do Agreste, Universidade Federal de Pernambuco, Caruaru.

Souza, E. S., Antonino, A. C. D., Angulo-Jaramillo, R., Maciel Netto, A., Montenegro, S. M. G. L., \& Borges, E. (2008). Variabilidade espacial dos parâmetros hidrodinâmicos de duas parcelas agrícolas no estado da Paraíba. Revista Brasileira de Ciência do Solo, 32, 1795-1804.

Vasconcelos, G. L. M. B. (2015). Caracterização hidrogeofísica de sedimentos típicos do leito seco do rio Capibaribe: experimentação e modelagem (Tese de doutorado). Centro de Tecnologia e Geociências, Universidade Federal de Pernambuco, Recife.

Vasconcelos, M. B. (2014). Poços para captação de águas subterrâneas: revisão de conceitos e proposta de nomenclatura. In Anais do $8^{\circ}$ Congresso Brasileiro de Águas Subterrâneas. Porto Alegre: Associação Brasileira de Recursos Hídricos.

World Health Organization - WHO, \& Unidt Nations Children's Fund - UNICEF. (2000). Global Water Supply and Sanitation Assessment (Report, 80 p.). USA: WHO/UNICEF.

\section{Contribuições dos autores:}

Tiago Oliveira Caetano: Contribuições: Realização dos testes para prospecção e análises granulométricas, realização das atividades do cadastro de usuários, análise dos resultados, redação do texto.

Anderson Luiz Ribeiro de Paiva: Contribuições: orientação e supervisão de todas as atividades, concepção dos trabalhos, análise dos resultados, redação e revisão do texto.

Simone Rosa da Silva: Contribuições: coordenação das atividades do cadastro de usuários, análise dos resultados, redação e revisão do texto.

Artur Paiva Coutinho: Contribuições: coordenação dos testes para prospecção e análises granulométricas, análise dos resultados, redação e revisão do texto.

José Almir Cirilo: Contribuições: acompanhamento dos trabalhos, análise dos resultados, redação e revisão do texto.

Jaime Joaquim da Silva Pereira Cabral: Contribuições: concepção dos trabalhos, análise dos resultados, redação e revisão do texto. 